\title{
Referenciação e construção de sentido: uma análise de formas nominais de implicação anafórica no tratamento jornalístico on-line a um objeto-de- discurso específico
}

\author{
Reference and sense construction: an analysis of \\ nominal forms of anaphora in the online journalistic \\ treatment of a specific object-of-speech
}

\section{Resumo}

O objetivo deste artigo é apresentar uma análise de formas nominais de implicação anafórica no processo de referenciação e suas nuanças na construção de sentidos em se tratando de um objeto-de-discurso específico - Barack Obama -, referenciado em textos publicados no jornalismo on-line. Para tanto, delimitaram-se como dados de pesquisa excertos de textos publicados no jornalismo on-line que tematizam a eleição presidencial nos Estados Unidos da América em 2008. Analisou-se como o presidente Barack Obama foi (re)categorizado nesses textos por meio de formas nominais de implicação anafórica. ${ }^{1}$ A fundamentação teórica é o processo de referenciação, concebido como atividade discursiva, conforme proposta por Mondada e Dubois (2003). Os resultados da análise reiteraram as considerações dos teóricos da referenciação no sentido de que determinadas formas de implicação anafórica, tendo em vista 
o potencial de recategorização do referente, atuam na construção sociocognitiva do objeto-de-discurso.

\section{Palavras-chave}

Referenciação, Formas nominais de implicação anafórica, Recategorização, Objeto-de-discurso, Barack Obama

\section{Abstract}

This paper aims at presenting an analysis of nominal forms of anaphora involved in the referencing process and their implications over the sense construction when dealing with a specific object-ofspeech - Barack Obama - referenced in texts from online journalism. In order to do that, excerpts of online journalism texts which refer to the presidential election in the United States of America in 2008 were chosen as research data. It was analyzed the way president Barack Obama was (re)categorized in these texts, through nominal forms of anaphora. The theoretical basis is the referencing process, taken as a discursive activity, as suggested by Mondada and Dubois (2003). The results of the analysis reinforce the reasoning of the researches of reference as long as some anaphoric forms, concerning the referent's recategorization potential, act on the sociocognitive construction of the object-of-speech.

\section{Keywords}

Reference, Nominal forms of anaphora, Recategorization, Object-of-speech, Barack Obama 


\section{Introdução}

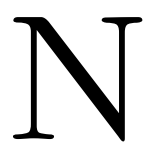

este estudo, partimos do pressuposto de que a linguagem não se constitui em um sistema de etiquetas para referenciar as coisas do mundo, e, sim, conforme propõem Mondada e Dubois (2003), como uma atividade intersubjetiva em que os sujeitos constroem, em suas práticas discursivas, sociocognitivas e culturalmente situadas, versões públicas de mundo.

Desse modo, adotando uma perspectiva de linguagem não referencial, ${ }^{2}$ este artigo toma como objeto de estudo a referenciação, com enfoque nas formas nominais de implicação anafórica em textos do jornalismo on-line, textos que instauram um processo cujos interactantes partilham versões públicas de um objeto-de-discurso específico, a saber: o presidente dos EUA "Barack Obama”. Acreditamos que esse objeto-de-discurso é particularmente interessante em se tratando da forma como é referenciado em determinados textos do jornalismo, tendo em vista que ele traz consigo uma série de componentes icônicos de natureza social, cultural e histórica: o primeiro negro presidente da maior potência mundial, país cuja história, como supomos amplamente sabido, carrega episódios emblemáticos de segregação racial.

Objetivamos evidenciar a função das formas nominais de implicação anafórica que atuam como um mecanismo de recategorização do referente, constituído como objeto-de-discurso, contribuindo para estabelecer a progressão referencial. Para tanto, inicialmente faremos uma breve exposição de conceitos que fundamentam este estudo, a saber: o deslocamento do conceito de referência para o de referenciação; a noção clássica ${ }^{3}$ de anáfora e a perspectiva sociocognitiva sobre os anafóricos. Na sequência, apresentaremos a exposição do percurso metodológico e, por fim, a análise realizada. 


\section{O deslocamento do conceito de Referência para o conceito de Referenciação}

A relação entre língua, mundo e significação caracteriza uma questão teórica que há muito tem sido foco de interesse nos estudos linguísticos. Essa questão tem como principal objetivo saber como a língua refere (ou representa) as "coisas" do mundo. Nos estudos linguísticos, há, no mínimo, duas perspectivas que enfocam tal problemática: a noção de referência tal qual é tomada por estudiosos racionalistas; ${ }^{4}$ e a teorização que, nos últimos anos, vem se opondo a essa corrente, proposta nomeada referenciação, explicitada em autores como Apothéloze Reichler-Béguelim (1995); Mondada e Dubois (2003); Koch (2002); Koch e Marcuschi (1998).

A noção de referência, que ainda persiste entre cognitivistas clássicos, ${ }^{5}$ implica considerar que há um mundo extramental dado a priori a ser internalizado em uma biblioteca mental. A referência caracteriza-se por ser um significado linguístico do referente, ou seja, uma representação extensional de referentes do mundo extramental (KOCH, 2002).

Os estudos sobre a referenciação, a seu turno, assumem a existência de uma realidade extramental cuja apropriação tem implicações sociais e culturais, que são chamadas de versões públicas de mundo. ${ }^{6}$ Nessa perspectiva, a referenciação constitui-se em uma atividade discursiva em que a realidade é mantida, construída, reconstruída e alterada pela forma como os sujeitos sociocognitivamente interagem com o mundo. Em outros termos, os sujeitos interpretam o mundo na interação com o entorno físico, social e cultural (KOCH, 2005).

Koch (2002) concebe a referenciação como uma atividade na qual o sujeito, na interação verbal, opera sobre o material linguístico, realizando escolhas significativas para representar estados de coisas, tudo isso com vistas à construção de sentido e em função do seu querer-dizer.

Dessa maneira, percebemos que há um deslocamento nos estudos sobre referência, uma vez que o conceito de referenciação carrega consigo o pressuposto de que a linguagem não se constitui em um sistema de etiquetas para referenciar as "coisas" do mundo, e sim, conforme propõem Mondada e Dubois (2003), como uma atividade intersubjetiva em que os sujeitos constroem, em suas práticas discursivas, sociocognitiva e culturalmente situadas, versões públicas de mundo, o que implica, reiteramos, uma visão de linguagem não referencial, ou seja, afastamo-nos do sentido clássico da referência. 
Em tal perspectiva tradicionalmente tomada de referência, as entidades designadas nas situações enunciativas referenciais são os objetos-do-mundo; já na perspectiva da referenciação, as entidades passam a ser objetos-dediscurso. De acordo com Koch (2002), os objetos-de-discurso não se confundem com a realidade extralinguística, mas reconstroem-na no processo de interação; além disso, são dinâmicos e, após serem introduzidos, são constantemente ativados, reativados, transformados, desativados e recategorizados. E ainda, Koch e Marcuschi (1998) propõem que os objetos-de-discurso não preexistem ao discurso, mas são constituídos no interior do próprio discurso, o que aponta para a plasticidade das significações linguísticas ${ }^{7}$. Essa percepção, evidentemente, não traz consigo relativismo inconsequente, dado o necessário compartilhamento de uma memória discursiva convergente entre os interlocutores.

Tendo em vista que a teoria da referenciação fundamenta este estudo, consideramos importante pontuar conceitos recorrentes nesta discussão. São eles: referência, remissão e retomada que, não raras vezes, são concebidos de maneira equivalente, quando, no entendimento de Koch (2002), se trata de construtos diversos.

Segundo a autora (p. 84), é possível estabelecer a seguinte relação de subordinação hierárquica entre esses termos:

(A) a retomada implica remissão e referenciação;

(B) a remissão implica referenciação e não necessariamente retomada;

(C) a referenciação não implica remissão pontualizada nem retomada.

A autora conceitua os termos da seguinte forma: a) referir - atividade de designação realizável por meio da língua sem implicar uma relação especular língua-mundo; b) remeter - atividade indexical na contextualidade; c) retomar - atividade de continuidade de um núcleo referencial, seja na relação de identidade ou não (KOCH, 2004, p. 59-60).

Até aqui buscamos mostrar o deslocamento da noção de referência para o conceito de referenciação; dando continuidade a esse percurso teórico, na sequência, traçaremos um paralelo entre a noção de anáfora tal qual é tradicionalmente concebida na literatura e a perspectiva sociocognitiva dos anafóricos no quadro teórico da referenciação. 


\section{A noção "clássica" de anáfora e a perspectiva sociocognitiva sobre os anafóricos}

$\mathrm{Na}$ literatura, encontramos distinções com relação ao conceito do fenômeno anafórico. No intuito de sistematizar os diferentes posicionamentos sobre o tema, é possível estabelecer dois grupos: um que corresponde a uma concepção de anáfora que está enraizada em uma leitura clássica e mais restrita do fenômeno, e outro, ancorado nos trabalhos recentes de base sociocognitiva, em que o fenômeno é compreendido de forma, entendemos, mais abrangente.

A noção de anáfora tradicionalmente postulada por autores como Halliday e Hasan, na obra seminal de 1976, é de fenômeno linguístico que possibilita o estabelecimento de uma relação semântica entre itens lexicais de um texto, sendo, pois, um importante elemento de coesão textual e operador de continuidade textual de suma relevância para a tessitura do texto.

Nessa concepção mais pontual, a anáfora é prioritariamente ligada à coesão textual, sendo um elemento estritamente responsável pelas retomadas de itens já textualizados. Além disso, nessa perspectiva, a anáfora tende a ser correferencial e ter um antecedente explícito, como podemos verificar no exemplo a seguir: ${ }^{8}$

Exemplo de retomada:

(1) O Presidente Lula sobrevoou as cidades catarinenses afetadas pela enchente. Ele ficou sensibilizado com a situação.

Em (1), a anáfora Ele retoma o antecedente $O$ Presidente Lula. Essa anáfora refere-se explicitamente ao SN antecedente, assim, em (1), a anáfora e o antecedente são correferenciais. ${ }^{9}$ Essa anáfora é chamada de anáfora pronominal por ser constituída por pronome. Além disso, é também considerada uma anáfora direta $(A D)$ pelo fato de retomar um referente previamente introduzido no enunciado, estabelecendo uma relação correferencial entre elemento anafórico e antecedente. Segundo Marcuschi (2005a, p. 55), "“...] a anáfora direta seria uma espécie de substituto do elemento por ela retomado".

Assim, nessa acepção com que tem sido tradicionalmente concebida, a anáfora é conceituada como um elemento que estabelece um continnum e que tem essencialmente a tarefa de retomada (Cf. exemplo 1), ou ainda, nos termos de Marcuschi (2005a), um processo de reativação de referentes prévios. 
A partir, porém, dos estudos sobre referenciação, que têm como pressupostos teóricos trabalhos de Apothéloz (1995); Mondada e Dubois (2003); Koch (2002); Marcuschi e Koch (1998) foi introduzida na Linguística Textual ${ }^{10}$ a discussão sobre a complexidade imbricada nos processos de referenciação textual, uma vez que nem sempre há uma absoluta identidade referencial entre anáfora e antecendente - ou seja, nem todas as anáforas são diretas, desempenhando o papel de "estar estritamente em lugar de" com que tradicionalmente têm sido tomado esse processo - e nem todas as informações para a interpretação de um texto estão situadas no contexto imediato. Assim, a ativação do conhecimento partilhado - a memória discursiva de que tratam Apothéloz; Reichler-Béguelin (1995) - entre os interlocutores tornou-se um fator relevante a ser considerado nos processos anafóricos.

Dessa forma, o uso de anafóricos parece, sob vários aspectos, extrapolar a mera função de retomada referencial estrita, assumindo um importante papel na construção de sentidos no texto, por ocasião do processo de referenciação. ${ }^{11}$ Inferimos, pois, que o conceito de anáfora foi ressignificado, passando a ser concebido também como elemento responsável pelas recategorizações de referentes no texto, no caso, por exemplo, de anáforas associativas, anáforas indiretas e encapsulamento anafórico. Sobre esse novo olhar, escreve Koch (2004, p. 69): "O emprego de expressões nominais anafóricas opera, em geral, a recategorização de objetos-de-discurso, isto é, tais objetos vão ser reconstruídos de determinada forma, de acordo com o projeto de dizer do enunciador".

\section{Sobre as formas nominais referenciais de implicação anafórica}

O termo formas ou expressões nominais referenciais tem sido atribuído às formas linguísticas constituídas, basicamente, de um determinante (definido ou demonstrativo), seguido de nome (KOCH, 2002). Essas formas nominais referenciais são responsáveis por dois grandes processos de construção do texto (e consequentemente do estabelecimento de sentidos no texto): o de retroação e o de prospecção.

Koch (2006, p. 2) apresenta as formas nominais referenciais como uma categoria maior, que inclui diferentes tipos de anafóricos. De acordo com a autora, as formas nominais referenciais são “[...] os grupos nominais com função 
de remissão a elementos presentes no cotexto ou detectáveis por meio de outros elementos nele presentes". Reiteramos que, na acepção da autora, a retomada é vista como uma "[...] atividade de continuidade de um núcleo referencial, seja numa relação de identidade ou não" (KOCH, 2004, p. 60). Isso reforça o que mostramos até aqui: a anáfora pode dar-se com ou sem absoluta identidade com referentes anteriormente expressos. Segundo Cavalcante (2003), no primeiro caso, pode haver simplesmente correferência entre a expressão anafórica e seu antecedente textual, ou ocorrer a recategorização deste. Então, na retomada não referencialmente estrita, essas formas anafóricas operam na recategorização dos objetos-de-discurso, isto é, na maneira como esses objetos serão reconstituídos, de forma a atender os propósitos comunicativos dos interlocutores.

Koch (2005) defende que, além da função de reconstrução dos objetos-dodiscurso, as formas nominais, de modo geral, têm uma orientação argumentativa. Nas palavras da autora: “[...] uma das funções textual-interativas específicas é a de imprimir aos enunciados em que inserem, bem como ao texto como um todo, orientações argumentativas conformes à proposta enunciativa do seu produtor" (KOCH, 2005, p. 35). Em nossa análise, como mostraremos a seguir, observamos a inserção dessa orientação argumentativa de que trata Koch nas formas nominais mobilizadas para, anaforicamente, referenciar e recategorizar o objetode-discurso "Barack Obama".

Na sequência, pontuaremos, de modo mais sistemático, a classificação das anáforas na visão de Koch (2006), teorização que foi utilizada como parâmetro para a análise do nosso objeto de estudo.

A primeira grande dicotomia, proposta pela autora, está nas anáforas correferencias e as não correferenciais. As anáforas correferencias referem-se aos casos das anáforas com retomada de antecedentes textuais. Essas anáforas podem ocorrer sem recategorização do referente ou com recategorização do referente, que são categorizadas da seguinte maneira:

1. Anáforas correferenciais sem recategorização:

- Por repetição: quando o núcleo da forma nominal repete o antecedente que está sendo retomado, seja de forma parcial, seja na íntegra. ${ }^{12}$

(2) Durante a conferência, o Professor Doutor José Mendonça pediu a palavra. O professor insinuou que o conferencista estava cometendo 
um sério engano. (2') Durante a conferência, o Professor Doutor José Mendonça pediu a palavra. Mendoncinha insinuou que o conferencista estava cometendo um sério engano.

- Por sinonímia: nesse caso a retomada de um antecedente ocorre através de expressões sinônimas ou parassinônimas (quase sinônimas).

(3) A polêmica parecia não ter fim. Pelo jeito, aquele bate-boca entraria pela noite adentro, sem perspectivas de solução.

2. Anáforas correferenciais com recategorização:

- Uso de hiperônimo: quando a anáfora por hiperonímia funciona necessariamente por recorrência a traços lexicais, isto é, o hiperônimo contém, em seu bojo, todos os traços lexicais do hipônimo.

(4) A aeronave teve de retornar à pista. O aparelho (aeronave) estava com defeito.

- Uso de nomes genéricos: trata-se da retomada do referente por meio de nome genérico: coisa, pessoa, negócio, criatura.

(5) Mistério no zoo

A polícia que investiga as mortes dos animais do Zoológico de São Paulo trabalha com duas hipóteses: envenenamento criminoso ou transmissão do veneno via ratos. Na última semana, a polícia apreendeu em uma loja de São Paulo frascos de um veneno cuja fabricação e venda estão proibidos no Brasil. O material apreendido contém a mesma substância encontrada nas vísceras dos animais mortos, o fluoracetato de sódio. (Época, 16/02/04)

- Uso de descrições nominais (definidas e indefinidas): trata-se de uma escolha entre as propriedades ou qualidades capazes de caracterizar o referente.

(6) O prefeito é especialmente exigente para liberar novos empreendimentos imobiliários, principalmente quando estão localizados na franja da cidade ou em áreas rurais.[...]. 
"O crescimento urbano tem de ser em direção ao centro, ocupando os vazios urbanos e aproveitando a infraestrutura, não na área rural que deve ser preservada", repete o urbanista que entrou no PT em 1981 como militante dos movimentos populares por moradia. (Quem matou Toninho do PT? In: Caros Amigos 78, setembro de 2003, p. 27.)

Já as anáforas não correferenciais referem-se àquelas em que não há identidade estrita com um antecedente textual. Essas, a seu turno, são agrupadas da seguinte forma:

1. Anáforas indiretas - quando um novo objeto-de-discurso é introduzido, sob modo do dado, em razão de algum tipo de relação com elementos presentes no cotexto ou no contexto sociocognitivo. Koch (2006) considera a anáfora associativa como um subtipo da anáfora indireta. No exemplo a seguir, tem-se um caso de anáfora indireta em que vagões e bancos são "ingredientes" de trem.

(7) Uma das mais animadas atrações de Pernambuco é o trem do forró. Com saídas em todos os fins de semana de junho, ele liga o Recife à cidade de Cabo de Santo Agostinho, um percurso de 40 quilômetros. Os vagões, adaptados, transformam-se em verdadeiros arraiais. Bandeirinhas coloridas, fitas e balões dão o tom típico à decoração. Os bancos, colocados nas laterais, deixam o centro livre para as quadrilhas.

2. Anáforas rotuladoras (encapsulamento anafórico) - trata-se de formas híbridas, referenciadoras e predicativas, que consistem em uma seleção particular e única entre uma infinidade de possibilidades lexicais para referenciar o objeto.

(8) É fácil apontar as razões de sucesso - ou fracasso - de um projeto após sua conclusão. O complicado é antecipá-las. Os executivos da Petrobrás, a maior empresa brasileira, enfrentaram um desafio assim há quatro anos, quando iniciaram a implantação do programa de gestão R/3 da SAP, batizada de projeto Sinergia. (Exame, $18 / 02 / 04)$ 
Até aqui expusemos o quadro teórico em que nos inserimos; na seção seguinte, apresentaremos, brevemente, os aspectos metodológicos que nortearam esta pesquisa.

\section{Percurso metodológico da pesquisa}

Os dados de pesquisa constituem-se em excertos de textos jornalísticos (dos gêneros discursivos: artigo e notícia), publicados no jornalismo on-line 13 $^{13}$ dos seguintes jornais: Folha on-line $e^{14}$ e $O$ Globo on-line ${ }^{15}$. Foram selecionados dos referidos textos exemplos de uso de formas nominais de implicação anafórica que referem o objeto-de-discurso "Barack Obama". Tais formas, a nosso ver, caracterizam-se como estratégias de negociação sociocognitiva para estabelecimento de sentidos para esse objeto em específico.

Optamos em analisar excertos de textos do jornalismo em função da contribuição desses textos para construções socioideológicas em grande escala, ao avaliar e validar os "já-ditos"; ao tornar "público" o que é privado; ao impor acento de valor sobre objetos-de-discurso que vão desde acontecimentos sociais até as pessoas e seu "dizer".

Para análise dos textos, como registrado anteriormente, assumimos como parâmetro da teorização sobre referenciação, mais especificamente, o conceito de formas nominais de implicação anafórica, ancorado em Koch $(2002,2004$, 2006), bem como a categorização dessas formas proposta pela autora.

De acordo com Koch (2006), quando se trata de anáfora sem identidade referencial estrita com um antecedente, o referente da expressão nominal terá de ser construído com base em um elemento ou conjunto de elementos presentes no cotexto, a que se tem denominado âncora ou gatilho do antecedente. Para tanto, faz-se necessária a mobilização do contexto sociocognitivo e/ou de aspectos do próprio entorno interacional. Assim, na análise dos textos, procuramos perceber como ocorre o processo de recategorização do objeto-de-discurso "Barack Obama" realizada por meio de formas nominais anafóricas, evidenciando o papel fundamental do compartilhamento sociocognitivo na construção de sentidos da referenciação anafórica desse objeto-de-discurso em especial. 


\section{O objeto-de-discurso Barack Obama}

No período de campanha eleitoral para a presidência dos EUA ${ }^{16}$, o candidato "Barack Obama" foi focalizado como um referente do mundo extramental, cujos atributos foram negociados, via construção de versões públicas de mundo. No processo de referenciação desse objeto-de-discurso em específico, destacamos, para as finalidades deste estudo, o uso de formas nominais referenciais de implicação anafórica.

De acordo com Koch (2002), as formas nominais referenciais desempenham importantes funções cognitivo-discursivas, entre elas a ativação e reativação de um referente na memória discursiva dos interactantes. Elas atuam como forma de remissão a elementos anteriormente apresentados no texto ou sugeridos pelo cotexto precedente, possibilitando a reativação na memória do interlocutor, ou seja, na alocução ou focalização na memória ativa deste.

Diante disso, podemos dizer que as nomeações atribuídas ao presidente "Barack Obama", em primeira instância, constituem-se em estratégias de ativação desse referente, veiculando informação nova. Depois de tais formas serem repetidas, reintroduzidas várias vezes no discurso, elas passaram a constituir estratégias de reativação desse referente, veiculando atributos a ele no limite do dado.

No percurso de análise, buscamos centrar o foco nas anáforas lexicais, tendo em vista que, em grande parte das vezes, elas trazem consigo progressão referencial, exigindo compartilhamento de versões públicas de mundo, o que as anáforas gramaticais ${ }^{17}$ não fazem ${ }^{18}$. Assim, foi possível apreender "os novos olhares", sociocognitivamente negociados, sobre esse objeto-de-discurso em particular: o presidente norte-americano "Barack Obama".

Mais do que um mecanismo de referenciação, as formas nominais de implicação anafórica funcionam como uma estratégia em alguns casos de progressão referencial porque trazem consigo recategorizações do referente que está ancorado na memória discursiva dos interlocutores. Por meio de uma negociação compartilhada entre esses interlocutores, observamos o uso de formas nominais de implicação anafórica atinentes ao objeto-de-discurso presidente "Barack Obama" que serão apresentadas e discutidas nesta seção.

Ao analisar as estratégias de retomada do referente, foi possível apreender que a recategorização do referente foi operada pelas formas nominais de implicação anafórica com base em "atributos" desse referente, atributos construídos no compartilhamento sociocognitivo e, como tal, historicamente 
situados. Em outros termos, a construção do objeto-de-discurso "Barack Obama" foi partilhada e negociada pelos indivíduos que interagem em um evento sócio-histórico particular, a saber, as eleições presidenciais dos EUA, ${ }^{19}$ evento que foi valorado socialmente e que teve um forte impacto no país onde ocorreu o processo eleitoral, como também em todo o mundo.

No percurso de análise, observamos que o objeto-de-discurso "Barack Obama" foi retomado e recategorizado por meio de uso de formas nominais de implicação anafórica que focalizam a origem étnica e social do objetode-discurso e a origem política do objeto-de-discurso.

A retomada e a recategorização do objeto-de-discurso por meio de formas nominais de implicação anafórica podem ser evidenciadas nas nominalizações utilizadas nos seguintes exemplos:

- Formas nominais de implicação anafórica que focalizam a origem étnica e social do objeto-de-discurso

(9) Enfim, nessa reta final, os eleitores de Barack Obama simplesmente não estão acreditando que podem ser testemunhas de um fato histórico, como muitos analistas não cansam de repetir por aqui, da eleição de um afro-americano presidente dos Estados Unidos.

(10) Obama presidente [...] A histórica eleição do primeiro presidente negro dos Estados Unidos é a cópia invertida da reeleição, em 2004, de George W. Bush.

(11) Barack Obama está sendo pressionado a matricular suas duas filhas numa escola pública de Washington - talvez seja mais fácil um negro ${ }^{20}$ se eleger presidente do que ele aceitar essa pressão. [...] um negro órfão, criado por uma avó, se tornou presidente.

- A origem política do objeto-de-discurso

(12) Obama, homem sereno de 47 anos, conseguiu aglutinar em volta de si a esperança de uns EUA menos agressivos e mais voltados para seus problemas internos, especialmente no front econômico [...]. O senador por Illinois eleito presidente terá desafios comparáveis aos de Franklin D. Roosevelt, quando assumiu a Casa Branca nas profundezas da Grande Depressão, em 1930. 
(13) Só dá Obama. [...] Se a eleição para presidente dos Estados Unidos fosse apenas na Califórnia, mais precisamente em San Francisco, o democrata Barack Obama poderia dormir tranquilo nessa terçafeira, dia quatro de novembro, já montando sua equipe de governo e delineando suas primeiras medidas. Por aqui, aonde quer que você vá, praticamente todo mundo diz que vai votar ou já até votou no candidato democrata.

(14) Obama propõe a retirada das tropas norte-americanas do Iraque. [...]. O candidato democrata é a favor da união civil entre pessoas do mesmo sexo e também do aborto.

(15) Obama, o candidado da esperança. Terremoto Obama [...]. Por que o jovem senador democrata personifica a esperança de mudanças pós-Bush?

Nesses exemplos apresentados, podemos observar, na maioria das vezes, o uso de formas nominais de implicação anafórica, de natureza correferencial e recategorizadora, tendo em vista que remetem ao objeto-de-discurso já textualizado e imprimem ao referente a construção de um "novo olhar".

No processo de referenciação do objeto-de-discurso "Barack Obama", destaca-se o uso de formas nominais, entre elas o uso de descrições nominais definidas (Dt. + Nome) como em: "o primeiro presidente negro dos Estados Unidos"; "o senador por Illinois eleito presidente"; "O candidato democrata" e "o jovem senador democrata". Nas formas definidas, segundo Koch (2002), o determinante pode ser artigo definido ou pronome demonstrativo, ou, ainda, um modificador: adjetivo, sintagma preposicional ou oração relativa.

Segundo Koch (2002), o uso de uma descrição definida implica sempre uma escolha entre as propriedades ou qualidades capazes de caracterizar o referente. Tal escolha se dá em virtude do contexto e, sobretudo, é determinada pelo querer-dizer do enunciador. Ainda, de acordo com a autora, trata-se da ativação, entre os conhecimentos pressupostos como partilhados com o(s) interlocutore(s) de traços do referente, no caso dos exemplos supracitados "Barack Obama", que o enunciador procura ressaltar (KOCH, 2002).

Assim, ao referenciar o objeto-de-discurso por meio de descrições definidas, as forma nominais de implicação anafórica cumprem sua função de especificar o referente e, além disso, operam, de forma significativa, na introdução 
do ponto de vista do enunciador, recategorizando o objeto. O uso de sintagmas com formas definidas cumpre a função de explicitar o compartilhamento de uma determinada visão entre autor e leitor. Assim, a forma definida introduz o já sabido, o já compartilhado entre os interactantes, o que supõe uma construção sociocognitiva da referência, com base em uma memória discursiva compartilhada.

Isso pode ser observado no exemplo (15), apresentado anteriormente.

A expressão definida "o jovem senador democrata" cumpre a função de referenciar (especificar) o objeto-de-discurso "Barack Obama", uma vez que faz parte da memória discursiva dos interactantes que um dos candidatos à presidência ocupa o cargo de senador da nação em questão e é membro do partido democrata. O uso da descrição definida 'jovem', a seu turno, também faz parte da memória discursiva dos interlocutores que um candidato à presidência de 47 anos de idade ${ }^{21}$ é tido como jovem, tendo em vista a responsabilidade e a experiência que se espera do indivíduo que ocupe o cargo maior da mais ovacionada nação do mundo. O uso do termo 'jovem' também pode ter sido escolhido em virtude do que vem na sequência do enunciado: 'esperança'. Dessa maneira, o fato de ser jovem também pode remeter à disposição para a 'mudança' que se espera do candidato a ser eleito.

Além de especificar o referente, o uso dessa descrição definida, ao inserir o termo 'jovem', evidencia o ponto de vista do enunciador, o que revela um caráter axiológico das descrições definidas. Vale salientar que a própria atividade de recategorização de um referente, em si mesma, tem uma natureza axiológica. Assim, ao passo que o sintagma das formas definidas, nesse caso específico, parece carregar consigo caráter axiológico relativamente explícito, observamos o uso de alguns SN's em que o juízo de valor se materializou, em nossa compreensão, de forma contundente, marcando o ponto de vista do enunciador. Esse aspecto dos SNs corrobora a instauração da argumentatividade no texto. Isso se relaciona à orientação argumentativa de que trata Koch (2004). Para a autora, constitui-se em uma manobra lexical bastante comum em gêneros opinativos, em que a escolha do nome-núcleo e/ou de seus modificadores constitui elemento preponderante na orientação argumentativa do texto, evidenciando traços de "ponto de vista" do enunciador.

No exemplo a seguir, evidenciamos as diferentes estratégias de instauração da argumentatividade e da posição valorativa do enunciador através de SNs. 
(16) O mundo espera Barack Obama como o Messias, enquanto, embora detalhes de sua vida sejam conhecidos, no fundo, ele é pouco mais que um grande mistério [...]. O Messias começa a trabalhar [...].

Na visão de Cavalcante (2003), ao recategorizar, muitas vezes através de metaforização, a forma nominal assume papel crucial, podendo evidenciar informações relativas ao ponto de vista do enunciador sobre o referente. Dessa maneira, o uso de metáforas como em "messias" contribuem para que se instancie a posição valorativa do enunciador.

Em síntese, as insistentes retomadas do objeto-de-discurso "Barack Obama", sobretudo como negro e como jovem, parecem remeter a uma aceitação tácita, construída sociocognitivamente, de que aí residem os atributos que distinguem o presidente eleito dos demais. Isso sugere que não se trata de um processo de referenciação asséptico (trazer um item do mundo para o discurso) e sim que se trata de um conhecimento sócio-historicamente construído e partilhado de atributos costumeiros e de atributos excepcionais nesse cargo tão diferenciado. Desse modo, ser negro e ser jovem seguramente são itens excepcionalmente importantes na retomada desse referente, porque aí reside a novidade ou a conquista, mas é uma novidade ou uma conquista que só fazem sentido a partir do compartilhamento da memória discursiva.

\section{Considerações finais}

Procuramos, com este estudo, mostrar que as formas nominais de implicação anafórica, além de contribuírem para estabelecer a continuidade temática e a progressão textual, também atuam como um importante mecanismo de recategorização do referente em objeto-de-discurso, contribuindo para a instauração dos propósitos discursivos do enunciador.

Com esse intuito, evidenciamos que, no processo de referenciação, as formas nominais de implicação anafórica utilizadas em textos do jornalismo on-line foram construídas através do compartilhamento sociocognitivo de versões públicas sobre o objeto-de-discurso específico, a saber: o presidente dos EUA, "Barack Obama".

As formas de nomear esse objeto-de-discurso constituíram-se no compartilhamento sociocognitivo dos interlocutores e foram tomadas como 
dadas, como elementos estabelecidos na memória discursiva dos interlocutores e, por isso, foram frequentemente introduzidas nos textos jornalísticos. Ressaltamos, ainda, que o uso de tais formas anafóricas corrobora a construção da argumentatividade, pois marcam a posição do enunciador diante do objetode-discurso e trazem consigo um caráter axiológico acentuado, pois, ao introduzir esse objeto através de itens lexicais como Messias revelam um movimento de referenciar, mas também de (des)qualificar o objeto-dediscurso.

\section{Notas}

1 "As nomeações mostram que os mecanismos da anáfora podem levar muito além da simples retomada de informação e contribuir para os aspectos mais especificamente construtivos do discurso." (APOTHÉLOZ, 2003, p. 73).

${ }^{2}$ Precisa ficar claro que não advogamos em favor de um relativismo inconsequente, porque, como escreve Koch (2004, p. 57): “[...] não postulamos uma reelaboração subjetiva, individual: a reelaboração deve obedecer a restrições impostas pelas condições culturais, sociais, históricas e, finalmente, pelas condições de processamento decorrentes do uso da língua.".

${ }^{3}$ Por noção "clássica" de anáfora, entendemos ser a concepção de que a anáfora é o elemento que "está em lugar de" e cujo referente é, em tese, facilmente recuperável no texto. Inferimos que os estudos de referenciação colocam em xeque, sob vários aspectos, os limites dessa concepção, ainda que conheçamos restrições de linguistas mais ortodoxos para os quais as anáforas associativas, por exemplo, constituem tão somente processos metonímicos.

${ }^{4}$ Referimo-nos à ideia segundo a qual a língua é um sistema de etiquetas que se ajustam mais ou menos bem às coisas, concepção que caracteriza a história do pensamento ocidental (MONDADA; DUBOIS, 2003) e que remete à teoria do mundo na mente (SMITH, 1980).

${ }^{5}$ Entendemos, aqui, por "cognitivistas clássicos" os adeptos do paradigma simbolista, sobremodo os de base racionalista cartesiana, que não se atêm à dimensão historicizada da cognição.

${ }^{6}$ Tais versões públicas demandam uma memória discursiva, que remete ao conceito de esquemas cognitivos internalizados pelo sujeito (APOTHÉLOZ; REICHLERBÉGUELIN, 1995). 
${ }^{7}$ Vale, aqui, o zelo explicativo de Marcuschi (2005b, p. 72): "Se o fato de não podermos dizer o mundo em si é inevitável, isso não significa que o mundo conhecido seja simples produto de nossas atividades cognitivas. Portanto, não há motivo para alvoroço: o mundo extramental existe. Contudo [...] todos os objetos de nosso conhecimento são produzidos no discurso, embora não se achem confinados ao discurso e podem ser intersubjetivamente comunicados. Também podemos acrescentar que, se por um lado, o mundo é independente de nossas crenças e sensações, por outro, nossas crenças e sensações não são totalmente independentes dele. Mas isso não justifica uma teoria da verdade como correspondência. Significa que não se pode imaginar que a língua seja um simples, acabado e eficiente instrumento a priori para construir ou retratar o mundo, e que o mundo, tampouco, está aí pronto, discreto e mobiliado a priori para ser designado. Com isso, nos afastamos tanto do antirrealismo como do relativismo sem precisar admitir o realismo externalista pura e simplesmente."

${ }^{8}$ Exemplo construído para este texto.

${ }^{9}$ Equivale a dizer que há uma identidade referencial entre anáfora e antecedente.

${ }^{10}$ Desde obra de 2002 (sem considerar os artigos anteriores), Koch vem discutindo os rumos da Linguística Textual; mantemos, aqui, a expressão com que essa área dos estudos linguísticos vem sendo mencionada desde a segunda metade do século XX, mas reconhecemos que, hoje, partidários de estudos dessa mesma área têm se dividido, dentre outros campos, entre o campo da enunciação e o campo da cognição.

${ }^{11}$ Trata-se, na verdade, em nosso entendimento, de conceber como processo anafórico o fenômeno que, até então, evidentemente havia no texto, mas não era assim categorizado.

${ }^{12}$ Os exemplos de formas nominais anafóricas expostas nesta seção foram extraídos de Koch (2006).

${ }^{13}$ Optamos por selecionar textos do jornalismo on-line por levar em consideração fatores como: facilidade de acesso em curto espaço de tempo a periódicos de geografias distantes e a contemporaneidade desse tipo de mídia.

${ }^{14}$ Disponível em: http://www.folha.uol.com.br/.

${ }^{15}$ Disponível em: http://oglobo.globo.com/.

${ }^{16}$ Estamos nos referindo à eleição presidencial ocorrida nos EUA no ano de 2008.

${ }^{17}$ Como exemplo de anáforas gramaticais podemos citar o uso de pronomes como: ele, alguns, etc. 
${ }^{18}$ Nessa distinção, é certo, está implicada a natureza lexical que esse recurso anafórico traz consigo e a consequente dimensão nocional, em contraposição à dimensão não nocional das categorias gramaticais, opostas, morfologicamente, às categorias lexicais.

${ }^{19}$ Obviamente, Barack Obama continua sendo um objeto-de-discurso que tem um forte apelo na mídia, sendo alvo de novas recategorizações, tendo em vista o evento de sua posse, como também os seus primeiros atos na qualidade de presidente dos EUA. Entretanto, neste artigo, delimitamos para composição da análise o processo de referenciação desse objeto-de-discurso no período de campanha eleitoral e o resultado da eleição.

${ }^{20}$ Ainda que este SN seja potencialmente uma retomada de Barack Obama, traz consigo, sem dúvida, conteúdo genérico, podendo extrapolar essa mesma retomada, o que, a nosso ver, tem relações com a ausência de adjetivação, visível na incidência posterior desse mesmo SN.

${ }^{21}$ Trata-se da idade de Barack Obama por ocasião das eleições; o que constituiu uma densa discussão sobre a "maturidade" do candidato para ocupar o cargo.

\section{Referências}

APOTHÉLOZ, Denis. Papel e funcionamento da anáfora na dinâmica textual. In: CAVAlCANTE, Mônica Magalhães; RODRIGUES, Bernadete Biasi (Org.). Referenciação. São Paulo: Contexto, 2003. p. 53-84.

APOTHÉLOZ, Denis; REICHLER-BÉGUELIN, Marie-José (1995), Construction de la référence et stratégies de désignation. In: BERRENDONNER, Alain; REICHLER- BÉGUELIN, Marie-José (Org.). Du Sintagme Nominal aux Objetsde-Discours. Neuchâtel: Université de Neuchâtel, 1995. p. 142-173.

CAVALCANTE. Mônica. Formas referenciais - uma proposta classificatória. In: Cadernos de Estudos Linguísticos, 44, Campinas, IEL/Unicamp, p. 105-118, 2003.

HALLIDAY, M.A.K.; HASAN, Ruqaiya. Cohesion in English. London: Longman, 1976.

KOCH, Ingedore G. V. Desvendando os segredos do texto. São Paulo: Cortez, 2002.

$\mathrm{KOCH}$, Ingedore G. V. Introdução à linguística textual. São Paulo: Martins Fontes, 2004.

KOCH, Ingedore G. V. Léxico e progressão referencial. In: RIO-TORTO, Graça Maria; SILVA, Fátima; FIGUEIREDO, Olívia Maria (Org.). Estudos em homenagem ao Professor Doutor Mário Vilela. Porto: Faculdade de Letras da Universidade do Porto, 2006. v. 1, p. 263-276. 
KOCH, Ingedore G. V.; MARCUSCHI, Luiz Antônio. Processos de Referenciação na Produção Discursiva. DELTA, v. 14, n. Especial, 1998.

MARCUSCHI, Luiz Antônio. Anáfora Indireta: o barco textual e suas âncoras. In: KOCH, Ingedore V., MORATO, Edwiges M.; BENTES, Anna Christina (Org.). Referenciação e discurso. São Paulo: Contexto, 2005a. p. 53-101.

MARCUSCHI, Luiz Antônio. A construção do mobiliário do mundo na mente. In: MIRANDA, Neusa Salin; NAME, Maria Cristina (Org.). Linguística e cognição. Juiz de Fora/MG: Editora da UFJF, 2005b. p. 49-78.

MONDADA, L.; DUBOIS, D. Construção dos objetos de discurso e categorização: uma abordagem dos processos de referenciação. In: CAVALCANTE, Mônica Magalhães; RODRIGUES, Bernadete Biasi (Org.). Referenciação. São Paulo: Contexto, 2003.

SMITH, Frank. Compreendendo a leitura. Porto Alegre: Artmed, 2003 [1980].

\section{Referências dos dados de pesquisa}

CANTANHÊDE, Eliane. Obama além de tudo sortudo. Disponível em: <http:// www1.folha.uol.com.br/folha/pensata/elianecantanhede/ult681u464302.shtml>. Acesso em: 20 jan. 2009.

CANZIAN, Fernando. Obama presidente. Disponível em: <http://www1.folha.uol.com.br/ folha/pensata/fernandocanzian/ult1470u464447.shtml>. Acesso em: 20 jan. 2009.

CRUZ, Valdo. Só dá Obama. Disponível em: <http://www1.folha.uol.com.br/folha/ pensata/valdocruz/ult4120u463723.shtml>. Acesso em: 20 jan. 2009.

DIMENSTEIN, Gilberto. Obama e a ex-futura prostituta de Brasília. Disponível em: <http://www1.folha.uol.com.br/folha/pensata/gilbertodimenstein/ ult508u468075. shtml>. Acesso em: 20 jan. 2009.

ESTADÃO. O Messias do Ocidente começa a trabalhar. Disponível em: <http:// www.estadao.com.br/internacional/not_int310027,0.htm>. Acesso em: 20 jan. 2009.

O GLOBO. Conheça o democrata Barack Obama. Disponível em: <http://oglobo. globo. com/mundo/eleicoesamericanas/mat/2008/06/05/conheca_democrata_ barack_obama-546676286.asp>. Acesso em: 22 jan. 2009. [* I incorporado.WMF *]. 